\title{
Antimicrobial Resistance : A Physician's Nemesis
}

\author{
Shruti S Bhide* and Anirudha V Potey \\ Department of Pharmacology and Therapeutics, Seth G S Medical College \& KEM Hospital, India
}

Submission: February 03, 2017; Published: February 10, 2017

*Corresponding author: Shruti S Bhide, Department of Pharmacology and Therapeutics, Seth G S Medical College \& KEM Hospital, Acharya Donde Marg, Parel, Mumbai, Maharashtra 400012, India, Email: shrutibhide72@gmail.com

\section{Opinion}

Emergence of New Delhi Metallo-beta-lactamase-1 (NDM1) gene in 2010 ticked a global alarm of newer mechanisms of resistance evolving in bacteria and becoming a worldwide public health problem [1]. This was an eyeopener and raises an important issue of antimicrobial resistance. It is estimated that around about 700,000 people die every year from drug resistant strains of common bacterial infections and the cost exceeds 20 billion USD. It is likely that by 2050 around 10 million lives each year may die and cost may rise to 100 trillion USD [2]. It has been almost six decades since the physicians have been battling the antimicrobial resistance when it was first detected with appearance of penicillin resistant staphylococci. Modifications to the existing antimicrobials by altering structure, pharmacokinetics, and drug action have been attempted, time and time again. But each time, resistance to the new mechanisms have risen, inflicting more severe infection to the patients. Today, existence of a "superdrug" seems a mirage, rather than a possibility. But emergence of "superbug" appears to be winning over making us to think new strategies. "Prevention is better than cure" is the motto today, in clinical practice of antimicrobials. However, the preventive approach has been threatened by inappropriate practices by prescribers. A recent European Union report suggested, significant multidrug resistance to common antibiotics is on rise in bacteria in different regions in Europe [3]. The CANWARD 2008 study in Canadian hospitals assessed prevalence of antimicrobial resistance of pathogens and reported high prevalence of MRSA 27.0\% [4]. Even developed nations have not escaped the clutches of antimicrobial resistance.

An important cause for emergence of resistant organisms is indiscriminate use of antibiotics by prescribers [5], which may be due to lack of appropriate antimicrobial use guidelines, lack of knowledge of the local pattern of infection or resistance, and abuse/casual attitude towards use of antimicrobials. Hospitals in many of the developed countries have formulated standard guidelines and brought them into practice. Robust antibiotic stewardship programs play a significant role. They update the practitioners on changes on the use of antimicrobials in hospital. Developing countries serve as reservoir for emergence of resistant organisms. Standard guidelines and antibiotic stewardship programs are difficult to initiate and implement. Final decision on the choice of antimicrobial rests on the physician.

Measures to curb the emergence of resistance need to be implemented actively. Use of antibiotics in humans, animals and meat industry should be exclusively limited to use for therapeutic cases. Spreading awareness about resistance by all possible ways and bringing transparency is the need of hour. Use of data and testing technology whenever possible will certainly be effective in prescription of antimicrobials. This will demand improved methods of diagnosis and diagnostic tools, preventing the transmission of micro-organisms and development of surveillance systems [6]. Other approaches to prevent resistance include improving prescribing practices, optimizing therapeutic regimens.

O'Neill has recommended fighting the antimicrobial resistance on 10 fronts - public awareness, limiting antibiotic use in agriculture and environment, surveillance of antimicrobial use, increase in human resources capital, increase in global innovation fund, maintaining sanitation and hygiene, developing vaccines and alternatives, developing rapid diagnostics for detecting the causative organism, developing new drugs and finally, international co-operative on Global front to battle antimicrobial resistance [2]. O'Neill has made an excellent effort to review the antimicrobial resistance and given appropriate measures for control. However, data regarding developing countries is lacking considerably. Disease burden and resistant pattern varies between the localities, regions and countries. Recommendations for developed and developing countries need to be addressed separately.

Global uniformity for definitions of multidrug resistant, extensively dug resistant and total/pan drug resistant should exist. Similarly, breakpoints for detecting resistance should be uniform. Currently there are differences in the standards provided by various organizations like CLSI, EUCAST and USFDA. 
If the war on antimicrobial resistance is to be fought on global front, a common standard for all developed and developing nations needs to be maintained [7].

New antibiotics that are being developed are being brought under strict regulatory control, to be indicated only when necessary. This is an essential step to prevent development of resistance to the new antibiotics [8]. Antibiotic innovation has been encouraged by the European Union and USFDA by providing incentives for the pharmaceutical companies. A trend for limited population antibacterial drug approval pathway is being encouraged for the Pharmaceutical Industry for trials in small limited population with resistant infections [9].

Antimicrobial resistance is holding back the physicians' from treating their patients effectively. A physician always intends well-being for the patient. Antimicrobial resistance should not discourage a physician for its use, but should encourage their rational use.

\section{References}

1. Kumaraswamy KK, Toleman MA, Walsh TR, Bagaria J, Butt F, et al. (2010) Emergence of a new antibiotic resistance mechanism in India, Pakistan, and the UK: a molecular, biological, and epidemiological study. The Lancet 10(9): 597-602.
2. Jim O’Neill (2016) Review on Antimicrobial resistance. Tackling drugresistant infections globally: Final report and recommendations.

3. EFSA (European Food Safety Authority) and ECDC (European Centre for Disease Prevention and Control) (2016) The European Union summary report on antimicrobial resistance in zoonotic and indicator bacteria from humans, animals and food in 2014. EFSA Journal 14(2): 207.

4. Zhanel GG, DeCorby M, Adam H, Mulvey MR, McCracken M, et al. (2010) Prevalence of antimicrobial-resistant pathogens in Canadian hospitals: results of the Canadian Ward Surveillance Study (CANWARD 2008). Antimicrob Agents Chemother 54(11): 4684-4693.

5. Ventola CL (2015) The antibiotic resistance crisis: part 1: causes and threats. P T 40(4): 277-283.

6. Ventola CL (2015) The antibiotic resistance crisis: part 2: management strategies and new agents. P T 40(5): 344-352.

7. Magiorakos AP, Srinivasan A, Carey RB, Carmeli Y, Falagas ME, et al. (2012) Multidrug-resistant, extensively drug-resistant and pandrugresistant bacteria: an international expert proposal for interim standard definitions for acquired resistance. Clin Microbiol Infect 18(3): 268-281.

8. Gould IM, Bal AM (2013) New antibiotic agents in the pipeline and how they can help overcome microbial resistance. Virulence 4(2):185-191.

9. Sinha MS, Kesselheim AS (2016) Regulatory Incentives for Antibiotic Drug Development: A Review of Recent Proposals. Bioorg Med Chem 24(24): 6446-6451.
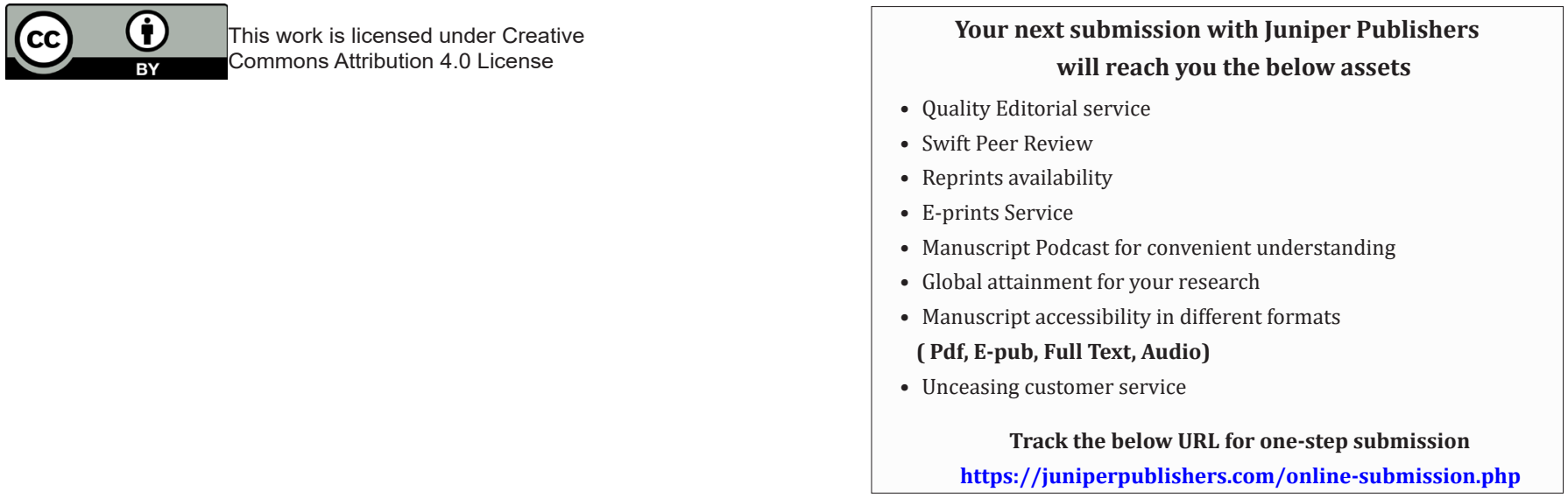